\title{
When the Bough Breaks: A Systematic Review and Meta-Analysis of Mental Health Symptoms in Mothers of Young Children during the COVID-19 Pandemic
}

Nicole Racine ${ }^{1}$, Ph.D., R.Psych., Rachel Eirich ${ }^{1}$, B.A., Jessica Cooke ${ }^{1}$, M.Sc., Jenney Zhu ${ }^{1}$, B.Sc., Paolo Pador ${ }^{1}$, Nicole Dunnewold ${ }^{2}$, M.L.I.S., Sheri Madigan¹, Ph.D., R.Psych.

Affiliations: ${ }^{1}$ Department of Psychology, University of Calgary, Calgary, Alberta, Canada, ${ }^{2}$ Health Sciences Library, Libraries and Cultural Resources, University of Calgary, Calgary, Alberta, Canada

Address correspondence to: Sheri Madigan, Ph.D, R.Psych, Canada Research Chair, Associate Professor, Department of Psychology University of Calgary, Calgary, AB, T2N 1N4, Canada, Phone: 403-220-6826; Email: sheri.madigan@,ucalgary.ca

Short title: Mental Illness in Mothers during COVID-19

Tables $=3$

Figures $=2$

Acknowledgements: The authors would like to acknowledge the contribution of members of the

Determinants of Child Development Laboratory at the University of Calgary, in particular,

Julianna Watt and Katarina Padilla for their contribution to data extraction.

Funding source: SM receives research support from the Canada Research Chairs program. NR is supported by a clinician-scientist award from Alberta Innovates, RE is supported by a graduate scholarship from the Social Sciences and Humanities Research Council, and JC is supported by a Vanier Canada Graduate Scholarship and an Alberta Innovates Scholarship. 


\begin{abstract}
Parents have experienced considerable challenges and stress during the COVID-19 pandemic, which may impact their well-being. This meta-analysis sought to identify: 1) the prevalence of depression and anxiety in parents of young children (< age 5) during the COVID-19 pandemic, and 2) sociodemographic (e.g., parent age, minority status) and methodological moderators (e.g., study quality) that explain heterogeneity among studies. A systematic search was conducted across four databases from January $1^{\text {st }}, 2020$ to March $3^{\text {rd }}$, 2021. A total of 18 non-overlapping studies $(9,101$ participants), all focused on maternal mental health, met inclusion criteria. Random-effect meta-analyses were conducted. Pooled prevalence estimates for clinically significant depression and anxiety symptoms for mothers of young children during the COVID19 pandemic were $27.4 \%$ (95\% CI: 21.5-34.3) and 43.5\% (95\% CI:27.5-60.9), respectively. Prevalence of clinically elevated depression and anxiety symptoms were higher in Europe and North America and among older mothers. Clinically elevated depressive symptoms were lower in studies with a higher percentage of racial and ethnic minority individuals. In comparison, clinically elevated anxiety symptoms were higher among studies of low study quality and in samples with highly educated mothers. Policies and resources targeting improvements in maternal mental health are essential.
\end{abstract}




\section{Key Findings}

- Pooled prevalence rates of clinically elevated depression and anxiety symptoms of mothers of young children (under age 5 years) during the COVID-19 pandemic were $27.4 \%$ and $43.5 \%$, respectively, indicating an increase from pre-pandemic estimates.

- Estimates for depression symptoms were higher among studies from Europe and North America, with a higher proportion of older mothers and a lower proportion of racial and ethnic minority participants.

- Estimates of anxiety symptoms were higher among low-quality studies, studies conducted in Europe and North America, studies with older mothers, and studies of highly educated mothers. 


\section{Statement of Relevance}

As a result of the COVID-19 pandemic, mothers have faced significant challenges, including loss of social support and childcare, loss of employment, and increased financial strain. Consequently, mental health difficulties in mothers have increased nearly two-fold for depression and three-fold for anxiety from pre-pandemic estimates. Given that infant mental health is inextricably linked to the mental well-being of the caregiver, policies that decrease familial stress, increase social and financial resources, and support the mental health of mothers during and after the COVID-19 pandemic are needed. 


\section{Background}

\subsection{Maternal mental health during the COVID-19 pandemic}

The COVID-19 pandemic and its associated consequences, including reduced social contact, economic hardship, and home confinement, have had a devastating global impact on the mental well-being of individuals across the lifespan (Vindegaard \& Benros, 2020). Indeed, longitudinal studies have demonstrated that there has been an increase in mental distress in the general population from before to during the COVID-19 pandemic (Pierce, Hope, et al., 2020). However, not all groups of individuals are impacted equally, with some members of the population disproportionately shouldering high levels of stress and mental health burden associated with the pandemic compared to others. One such group are women with infants and young children under the age of 5. In a large population-based study in the United Kingdom, some of the highest increases in mental distress during the early months of the pandemic were among mothers of young children (Pierce, Hope, et al., 2020). Cross-sectional studies during the COVID-19 pandemic have also demonstrated high prevalence rates of mental health symptoms among pregnant women and mothers, including depression and anxiety, with rates well above those that existed before the COVID-19 pandemic (Cameron et al., 2020; Tomfohr-Madsen et al., 2021). Given that the health and well-being of infants and young child are inextricably linked to the well-being and functioning of their caregiver (Prime et al., 2020; Rogers et al., 2020; Schore, 2001), it is critical to understand the extent to which the COVID-19 has impacted maternal mental health as well as factors that may be exacerbating these effects. Particular attention to addressing the mental health needs of mothers of young children during and in the aftermath of the COVID-19 pandemic will be critical to rebuilding healthy citizens and communities.

\subsection{Maternal Mental Health and Infant Developmental Health}


Global estimates before the COVID-19 pandemic based on meta-analyses indicate that the prevalence rate of postpartum depression in mothers is approximately $17 \%$ (Shorey et al., 2018) and 15\% for postnatal anxiety (Dennis et al., 2017). Research pre-pandemic has demonstrated that maternal mental illness, particularly maternal depression, and anxiety, are consequential for childhood and adolescent development (Goodman et al., 2011; Rogers et al., 2020). To optimally thrive, infants and young children are particularly reliant on their caregivers to meet their basic needs (e.g., food, sleep, etc.), as well as their relational (e.g., sensitive parenting; conversational turns) and developmental needs (e.g., language input) (Anderson et al., 2021; De Wolff \& van Ijzendoorn, 1997; Field, 2010). Maternal mental illness during these critical years can disrupt both the quality of the relational inputs the child receives (Bernard et al., 2018; Sohr-Preston \& Scaramella, 2006) as well as the stability of the environment in which the child develops (Gelfand \& Teti, 1990).

The postpartum period, transition to motherhood, and early years of a child's life are developmental stages associated with increased vulnerability to mental health difficulties for mothers (Cameron et al., 2016; Shorey et al., 2018). Indeed, research suggests that experiencing depression is associated with harsh or hostile parenting, less sensitive responsive parenting, and increased challenges in the parent-child relationship (Badovinac et al., 2018; Barnes \& Theule, 2019; Hentges et al., 2021; Lovejoy et al., 2000). The presence of maternal mental health difficulties in the early years are also associated with disruptive caregiving behaviours that have the potential to disrupt the attachment relationship (Lyons-Ruth, 2002). Similarly, anxious parenting, including overprotection and heightened communication about threat, have also been associated with increased post-traumatic stress symptoms in children following natural disasters (Cobham \& McDermott, 2014). 


\subsection{Unique experience of mothers of young children (0-5 years) during the COVID-19 pandemic}

Experiencing the significant shifts and stressors associated with early parenthood during a global pandemic may have exacerbated maternal mental health difficulties, particularly for mothers dealing with predisposing risks (e.g., poverty) or pre-existing mental health concerns. While increases in depressive and anxiety symptoms were experienced across the general population during the COVID-19 pandemic, mothers of young children were at increased risk for mental health difficulties for several potential reasons including loss of social support, loss of childcare, economic hardship, and the widening of social disparities.

First, because of public health requirements (i.e., social distancing, lockdown measures, and stay at home orders) many of the traditional mechanisms by which mothers of young children access and receive social support were suspended. For example, being able to gather with family or friends, socialize with other parents, or participate in playgroups or other activities were halted. Social support, particularly in the early years of parenting, has been identified as a critical ingredient for maternal mental health and wellbeing (Hetherington et al., 2018). Indeed, social support is a protective factor against depression and anxiety in mothers of young children (Mathiesen et al., 1999; Racine et al., 2019) and has been shown to moderate the association between perinatal stress and symptoms of depression and anxiety (Razurel \& Kaiser, 2015). To date, a large population-based study has demonstrated that adults with low social support were at increased risk of elevated trajectories of depression during thee COVID-19 pandemic as compared to those with adequate support (Iob et al., 2020). Thus, the direct loss of social support outside the immediate household during the COVID-19 pandemic, and the associated increased feelings of loneliness, isolation, and stress (Ollivier et al., 2021), particularly at a salient 
development juncture (i.e., transition to parenthood) when increases in social support are most needed, could have precipitate increased mental health difficulties in mothers of young children.

Second, when the COVID-19 pandemic was declared a global crisis, childcares and schools around the world closed their doors in order to mitigate virus spread (Lee, 2020). In many jurisdictions, schools and childcares remained closed for several months leaving parents with the difficult task of balancing their employment and parenting responsibilities (Sevilla \& Smith, 2020). Unlike older children, who can self-initiate and complete tasks independently, infants and young children require constant and consistent supervision. It is well known that when stressors mount and the availability of resources decrease, mental distress is a likely outcome (Selye, 1955). Thus, increased stress associated with balancing multiple roles may also have precipitated an increase in mental health difficulties for mothers (Calarco et al., 2020 ; Cheng et al., 2021). Notably, this may occur uniquely in mothers, not fathers, as research has shown that in heterosexual couples, mothers were more likely to care for children and be responsible for domestic labour during the COVID-19 pandemic (Zoch et al., 2021). Indeed, a study in the UK of dual working parents during the pandemic showed that women were responsible for $65.5 \%$ of the additional childcare required during the pandemic (Sevilla \& Smith, 2020), which may have led to increased stress and subsequent mental health symptomatology in mothers.

Third, in many households, the loss of support from family as well as lack of childcare led to a reduction of work hours or loss of employment income. In families with young children, this was especially the case for mothers as compared to fathers (Carlson et al., 2020). The disparity in loss of employment and income for mothers during the COVID-19 pandemic has been referred to as the "motherhood penalty" (Dias et al., 2020). Loss of employment and 
income have been shown to be robust catalysts for increases in mental health symptomatology (Goldman-Mellor et al., 2014). For example, a study of mothers with school-aged children demonstrated that in households that had lost income or employment during the pandemic, rates of clinically significant anxiety and depression were $6 \%$ and $7 \%$ higher, respectively, than in families who had not lost income or employment (Racine et al., 2021). Additionally, economic data from Canada demonstrates that households under the age of 35 years experienced the greatest income declines in the early months of the pandemic (Statistics Canada, 2021), which is the demographic most likely to be parenting young children. Furthermore, evidence from countries around the globe, including both low-middle- and high-income countries indicate that the COVID-19 pandemic was associated with large decreases in family incomes as well as increased food insecurity (Hamadani et al., 2020; Patrick et al., 2020). Taken together, loss of employment, financial stress, and food insecurity during the COVID-19 pandemic, particularly among parents, may have created a context that was ripe for increases in maternal mental health difficulties.

As the COVID-19 pandemic has evolved, empirical evidence has demonstrated that social disparities that existed before the pandemic among single, racial, and ethnic minority, and socially disadvantages mothers have been severely exacerbated (Etowa \& Hyman, 2021; Hertz et al., 2020). Far from the great equalizer, the COVID-19 pandemic has increased pre-existing social and health inequalities among traditionally marginalized groups around the globe. For example, in a large, longitudinal survey in the United States, Black adults were 3 times more likely than Whites to report employment loss, food insecurity, or unemployment because of the COVID-19 pandemic (Perry et al., 2021). Food insecurity and economic hardship have also been documented to be more severe among those without a university education and in women (Perry 
et al., 2021). Cross-sectional data on depressive symptoms in mothers of young children during the pandemic demonstrated that lower family income before the pandemic was associated with an increased likelihood of depressive symptoms during the pandemic (Cameron et al., 2020). Taken together, social inequalities with regards to health and mental health that existed prior to the pandemic for marginalized women, including reduced access to health and mental health care, racism, and poverty (Parker, 2021), have become even more entrenched (Hooper, 2020), leading to larger increases in mental health difficulties for mothers of young children who experience poverty, racism, and low education.

\subsection{Potential moderators associated with increases in maternal mental health symptoms during the COVID-19 pandemic}

There are two important gaps in the literature with regards to understanding the mental health of mothers of young children during the COVID-19 pandemic. First, while preliminary studies have been conducted examining the prevalence of depression and anxiety symptoms of mothers during the pandemic, obtaining a pooled estimate of clinically significant mental health symptoms would help policymakers and mental health providers make decisions with regards to resource allocations and increases to address the increased rates of maternal mental health difficulties. Second, there is currently significant variability in effect size estimates across studies. Specifically, for depression, prevalence estimates range from $6.3 \%$ (Silverman et al., 2020 ) to $61 \%$ (Harrison et al., 2021) and for anxiety prevalence estimates range from $13.5 \%$ (Hamadani et al., 2020) to $61 \%$ (Harrison et al., 2021). When there is significant variability in prevalence estimates across studies, it suggests that a potential third variable (i.e., a moderator) may be at play. Thus, an important gap that the current meta-analysis seeks to address is to 
examine potential moderating variables that may play a role in explaining heterogeneity among study estimates.

Several potential moderators may be playing a role in explaining between study heterogeneity for prevalence rates of maternal depression and anxiety during the COVID-19 pandemic including maternal age, infant age, minority status, maternal education level, and marital status. Specifically, prior to the pandemic, research has shown that younger mothers may be at increased risk for mental health symptomatology due to lower levels of social support and financial stability (Van Lieshout et al., 2020). Being the mother of a younger infant also has the potential to be associated with higher prevalence rates of mental health difficulties since the first months postpartum have been identified as a sensitive period for maternal mental health difficulties, particularly depression (Vesga-Lopez et al., 2008). Furthermore, as outlined in the previous section, in additional to experiences of interpersonal and systemic racism, racial and ethnic minority mothers have experienced greater disparities in terms of employment loss and income during the COVID-19 pandemic, which on may be contributing to increases in mental health symptomatology. Furthermore, other indicators of socioeconomic status such as level of education or marital status, may also be associated with increases in mental health symptomatology given that previous research has shown that financial strain and income are associated with increases in maternal mental health during the pandemic (Racine et al., 2021).

It is also possible that methodological characteristics of the studies may be contributing to heterogeneity across studies. Specifically, studies of lower methodological quality from selfselected or non-probability samples may include individuals with higher mental health difficulties who self-selected to participate (Pierce, McManus, et al., 2020). Additionally, preliminary research evidence suggests that as time passes during the pandemic that a decrease in 
anxiety is being observed across waves, while suicidal ideation has been shown to increase over time, and depression has been shown to stay the same (O'Connor et al., 2020; Robinson et al., 2021). Lastly, geographical location may play a role in self-reports of mental health difficulties as pervious research has shown that mental health stigma varies across cultural groups, with higher levels of mental health stigma being observed in Asian Americans than other cultural groups (Abdullah \& Brown, 2011). In summary identifying the sociodemographic and methodological factors that moderate the variability in prevalence rates across studies may help inform the development of and investment in programs, policies, or governmental support that could improve mental health symptoms among the mothers of young children.

\subsection{Rationale for review}

An important step to inform resource allocation and program planning is to understand the magnitude of the impact of COVID-19 on the mental health of mothers with young children as well as associated factors that may amplify or attenuate elevations in mental health difficulties.

To address this research gap, as well as inform policy and practice, the current systematic review and meta-analysis examines the prevalence of mental health difficulties, specifically depression and anxiety, among mothers of children under the age of 5 years during the COVID-19 pandemic. To our knowledge, a synthesis on the mental health difficulties of mothers of infants and young children has not been conducted to date. Additionally, to inform for whom and under what circumstances maternal mental health may be most at risk, we must examine candidate moderator variables. Thus, in the current meta-analysis we also examine sociodemographic (i.e., maternal age, child age, minority status, education, and marital status) and methodological (i.e., study quality, month of the year, and geographic region) moderating variables that may account for variability in prevalence rates across studies. Based on previous literature, we hypothesized 
that samples with a higher proportion of mothers who were young, had younger children, were of minority status, had lower education, and were less likely to be married would have higher prevalence rates of anxiety and depressive symptoms. We also hypothesized that lower quality studies and those conducted in Western Countries (i.e., North America and Europe) would also have higher prevalence rates.

\section{Method}

\subsection{Search strategy and study identification}

The review is reported in accordance with the Preferred Reporting Items for Systematic Reviews and Meta-Analyses guidelines (Moher et al., 2009) and the protocol was pre-registered in PROSPERO [CRD42021240457]. Searches were conducted in Ovid MEDLINE, Embase, Cochrane Central Register of Controlled Trials (CENTRAL), and APA PsycINFO up to March 3, 2021 by a health sciences librarian up to March 3, 2021. A date restriction was applied to capture studies from the beginning of the COVID-19 pandemic onwards. No language restrictions were applied, and search strategies combined search terms falling under three themes: 1) mental health and illness (including, but not limited to, anxiety, depression, and posttraumatic stress); 2) COVID-19; and 3) parents (see Supplementary Table 1 for example of search strategy in Ovid MEDLINE). Terms were searched as both keywords and database subject headings as appropriate. Both adjacency operators and truncation were used to capture phrasing variations in keyword searching. A hand search was also conducted on March 1st, 2021 and one additional study was added to the search results.

\subsection{Inclusion and Exclusion Criteria}

The inclusion criteria for the current review are detailed as follows: (1) data was collected during the COVID-19 pandemic, (2) the study sample represented a general population of 
biological parents with children 5 years or younger; (3) the proportion of parents meeting clinical cut-off scores or falling in the moderate-to-severe symptom range of depression or anxiety using a validated self-report measures was reported in the study (i.e. number of parents meeting the cut-off divided by the total number of parents in the sample); (4) the study was empirical; and (5) written in English. We did not include samples of parents who had chronic health conditions, parents who had contracted COVID-19, or who identified as having a psychiatric condition or having received psychiatric treatment prior to the pandemic. Studies that were not empirical in nature, such as case studies or qualitative syntheses, were also excluded. Only one study from a given sample was included in the meta-analysis. As such, if more than one study was retrieved using the same sample, the study with the largest sample size and most comprehensive information was retained. All studies included in the current review were published. Although the review set out to examine mental illness in parents during the COVID-19 pandemic, only studies including data on mothers met inclusion criteria. As such, the review focuses on the mental health of mothers.

Using Covidence software, five coders reviewed all titles and abstracts that were obtained from the search and evaluated them against eligibility criteria. To establish reliability for the abstract review, $20 \%$ of abstracts were double coded and an average random agreement probability of .851 to .871 was obtained. Once the full texts were retrieved from the abstract that met inclusion criteria, the full texts were reviewed by 3 study authors to ensure the full texts should be included. All full texts were reviewed by two study authors and disagreements were resolved via consensus.

\subsection{Data extraction: Coding}


Once studies were established as meeting inclusion criteria, five coders extracted information on study characteristics, prevalence rates for anxiety and depression, as well as potential moderators. Coders used a comprehensive coding manual developed by the first and last authors. All studies were extracted by two coders and discrepancies were discussed and final consensus was reached. If a study had more than one data point, the most recent data collection point was retained. Additionally, in a study where findings were reported separately for more than one child age group under the age of 5 years, a pooled prevalence rate for children under the age of 5 years was calculated.

The following moderators were extracted: (1) parent age at the time the mental health measure was administered (continuously as a mean); (2) child age at the time of data collection, (3) country in which the study was conducted, (4) month of the 2020 calendar year when data was collected (ranging from 1-12), (5) percentage of the sample that was female, (6) the percentage of the sample that was an ethnic minority, (7) the percentage of parents who had a university education, and (8) the percentage of parents who were married. Education and marital status were extracted as proxies for socio-economic status as few studies reported on the income of participants or the nature of the reporting was too heterogenous to extract. Study quality was also coded for each study and is described below.

\subsection{Study Quality}

Given the rapidly evolving nature of the COVID-19 pandemic and the need to abbreviate the amount of time taken to conduct the meta-analysis, a brief 5-item study quality measure was adapted based on the National Institute of Health Quality Assessment Tool for Observation Cohort and Cross-Sectional Studies (National Heart \& Blood, 2014). The brief study quality measure had five items which included: (1) outcome was assessed with a validated measure; (2) 
study was peer-reviewed versus unpublished; (3) study had a response rate of at least 50\%; (4) depression or anxiety was assessed objectively (i.e., diagnostic interview); and (5) the study had sufficient exposure time to COVID-19 (i.e., at least one week since the onset of COVID-19 in the specific country where the study was conducted). Each item of the study quality score received a score of 0 (no) or 1 (yes) with total potential scores ranging between 0 and 5 . If information was not clear, not reported, or missing within the study, the study quality item was marked as 0 . The criteria for the study quality scoring measure as well as the detailed scores are provided in Table 2 and Table 3 of the Supplemental Material.

\subsection{Statistical analyses}

\subsubsection{Pooled effect sizes}

Random effects models were used in the current meta-analysis as heterogeneity is assumed across studies and is the most conservation analytic strategy (Borenstein et al., 2010). Pooled prevalence estimates were weighted by the inverse of their variance, which gives greater weight to studies with large sample sizes included in the analyses. Separate meta-analyses were conducted for each of the maternal mental health outcomes: depression and anxiety. All analyses were conducted using Comprehensive Meta-analysis (CMA version 3.0), a well-established software for conducting meta-analyses (Borenstein et al., 2013). Pooled prevalence estimates with associated $95 \%$ confidence intervals (CIs) around the estimate were computed for both depression and anxiety symptoms. We weighted pooled prevalence estimates by the weight of the inverse of their variance, which gives greater weight to large sample sizes.

\subsubsection{Heterogeneity and moderator analyses}

Between study heterogeneity was evaluated using the $Q$ and $I^{2}$ statistics. Using guidelines established by Borenstein and colleagues (2009), a significant $Q$ statistic suggests moderator 
analyses should be explored, while the degree of variability across studies is indicated by the $I^{2}$ statistic. When an $I^{2}$ value exceeds $75 \%$, moderator analyses should also be explored. Given that only 8 studies were retrieved for the anxiety meta-analysis, we examined categorical moderators when the number of studies in each category exceeded two. Random-effects meta-regressions were calculated in CMA to explore the effect of continuous moderators. To explore publication bias, we used the Egger test (Egger et al., 1997) and explored the funnel plots for asymmetry. We also used Duval and Tweedie's trim and fill method to examine whether the pooled effect size needed to be adjusted based on publication bias (Duval \& Tweedie, 2004).

\section{Results}

As reported in the PRISMA flow diagram (see Figure 1), our search yielded 1627 nonduplicate records, of which 133 full-text articles were retrieved and evaluated against inclusion criteria. A total of 18 non-overlapping studies met full inclusion criteria (Cameron et al., 2020; Chaves et al., 2021; Fallon et al., 2021; Hamadani et al., 2020; Harrison et al., 2021; Loret de Mola et al., 2021; Molgora \& Accordini, 2020; Oskovi-Kaplan et al., 2020; Ostacoli et al., 2020; Pariente et al., 2020; Silverman et al., 2020; Spinola et al., 2020; Stojanov et al., 2020; Suhariati et al., 2020; Sun et al., 2020; Suzuki, 2020; Zanardo et al., 2020; Zanardo et al., 2021).

\subsection{Study characteristics}

Study characteristics for all 18 included studies are presented in Table 1. There 16 studies that provided data for clinically elevated depressive symptoms and 8 studies that provided data for clinically elevated anxiety symptoms. Across all included studies, 9,101 participants were included, all of whom were female. The mean age of mothers was 30.68 years (age range, 24.134.77) and the mean age of children was 10.47 months (age range 0.07 to 60 months). On 
average, $26.73 \%$ of the women across samples were identified as belonging to ethnic minority groups. Of the samples included, on average, $52.80 \%$ of women had at least a university education and $62.76 \%$ were married. With regards to geographic region, nine studies were from Europe (50.0\%), two from East Asia (11.1\%), two from North America (11.1\%), two from the Middle East (11.1\%), one from South Asia (5.6\%), one from South East Asia (5.6\%), and one from South America (5.6\%). The average study quality score was 3.33 (range 3 to 4 ).

\subsection{Pooled prevalence of clinically elevated maternal depressive symptoms during COVID-19}

The random-effects meta-analysis of 16 studies yielded a pooled prevalence rate of .274 (95\% CI: .215, 0.343; Figure 2) or $27.4 \%$ for clinically elevated depressive symptoms. The funnel plot was symmetrical (see Supplemental Figure 1), and the Egger test was statistically significant $(\mathrm{p}=.03)$. No studies were identified to trim or impute using Duval and Tweedie's trim and fill technique.

\subsubsection{Moderator analyses for pooled prevalence of clinically elevated depressive} symptoms

Significant between study heterogeneity was identified $\left(Q=462.326, p<.001, I^{2}=96.76\right)$; thus, potential moderators were explored based on all included studies (see Table 2). Three moderators were significant for maternal depressive symptoms: geographical region, maternal age, and ethnic minority status. The prevalence of clinically significant depression was higher in studies from Europe and North America $(\mathrm{k}=11$; rate $=.322,95 \%$ CI: $.243, .414 ; \mathrm{p}<.001)$ compared to studies from South America, the Middle East, or Asia $(\mathrm{k}=5$; rate $=.185,95 \%$ CI: $.112, .289 ; \mathrm{p}<.001)$. Prevalence rates varied as a function of maternal age $(\mathrm{b}=.185,95 \% \mathrm{CI} . .03$, .33) with depressive symptoms being higher in studies with older mothers. Lastly, ethnic 
minority was a significant moderator whereby studies that had higher percentages of individuals of ethnic minority status had lower depressive symptom prevalence rates $(\mathrm{b}=-.03,95 \% \mathrm{CI}$ :-.04, .02). No other significant moderators were detected.

\subsection{Pooled prevalence of clinically elevated maternal anxiety symptoms during COVID-}

19

The overall pooled prevalence of clinically elevated anxiety symptoms across 8 studies was .435 (95\% CI: .275, .609; Figure 2) or 43.5\%. The funnel plot was somewhat asymmetrical (see Supplemental Figure 2), and the Egger test was not significant $(p=.10)$. When Duval and Tweedie's trim and fill method was applied to account for publication bias, one imputed study was identified. Thus, the adjusted pooled effect size is .410 (95\% CI: .266, .570; Figure 2) or $41.0 \%$.

\subsubsection{Moderator analyses for pooled prevalence of clinically elevated anxiety symptoms}

For the eight studies reporting on anxiety, there was significant between-study heterogeneity $\left(Q=783.923, p<.001, I^{2}=99.11\right)$ and thus, potential moderators were examined (see Table 3). There were four significant moderators that emerged for symptoms of anxiety: study quality, geographical region, maternal age, and maternal education. The prevalence of clinically significant anxiety was higher in studies deemed to be of poorer study quality $(\mathrm{k}=6$; rate $=.529,95 \%$ CI: $.421, .634 ; \mathrm{p}<.001)$ compared to studies with better study quality scores (k $=2$; rate $=.200,95 \%$ CI: $.107, .342 ; \mathrm{p}<.001)$. The second significant moderator was geographical region, the prevalence of clinically significant anxiety was higher in studies from Europe and North America $(\mathrm{k}=5$; rate $=.529,95 \% \mathrm{CI}: .401, .652 ; \mathrm{p}<.001)$ compared to studies from South America, the Middle East, or Asia $(\mathrm{k}=3$; rate $=.279,95 \%$ CI: .164, .433; $\mathrm{p}<.001)$. 
Third, prevalence rates varied as a function of maternal age $(b=.18,95 \% \mathrm{CI}: .005, .35)$ with anxiety symptoms being higher in studies with older mothers. Lastly, maternal education was a significant moderator of anxiety prevalence rates with more highly educated mothers exhibiting higher clinically significant symptoms of anxiety ( $b=.02,95 \% \mathrm{CI}: .003, .04)$.

\section{Discussion}

The current meta-analysis and systematic review of cross-sectional studies during COVID-19 found a pooled prevalence of $27.4 \%$ for maternal depression and $43.5 \%$ for maternal anxiety symptoms. Thus, approximately 1 in 4 mothers of young children are experiencing clinically significant depression during COVID-19, while 1 in 2 are experiencing anxiety. When comparing these rates relative to pre-pandemic estimates of $17 \%$ for clinically elevated depression and 15\% for anxiety (Dennis et al., 2017; Horwitz et al., 2007; Shorey et al., 2018), a doubling and tripling of depression and anxiety symptoms, respectively, has been observed for mothers of young children during COVID-19. Public health measures implemented for managing the spread of COVID-19 have left some families grappling with job losses, financial hardship, and a loss of social and childcare supports. These substantive changes likely have downstream consequences for maternal mental health, as women take on more household duties to fill the void of uprooted household and childcare supports and face uncertainty about when supports will be re-established (Carlson et al., 2020).

There are several explanations for why maternal mental distress may be so impacted by COVID-19. First, past research has identified social support as being an important factor in the wellbeing of mothers, such that a lack of social support has been associated with mental health concerns (Bullock et al., 2002; Howard et al., 2014). Given the COVID-19 pandemic has required populations to engage in social distancing procedures and stay-at-home orders, mothers 
may represent a population that is particularly harmed by a reduction in social support. Second, mothers of young children may also be at greater risk for depression and anxiety during the COVID-19 pandemic due to the stress associated with balancing multiple roles (e.g., childcare, homeschooling, work, domestic tasks). Closures of schools and daycare facilities have forced many parents to balance paid work and childcare and previous literature has suggested that women tend to take on a greater portion of childcare and household labour (Horne et al., 2018). Existing research has found that mothers, particularly those with younger children, were more likely to reduce paid work compared to fathers during the COVID-19 pandemic to accommodate for childcare and homeschooling (Collins et al., 2020). Further, research has found that the increased demands of household work mothers face has been associated with stress and frustration (Hjalmsdottir \& Bjarnadottir, 2020), which may have exacerbated maternal mental health difficulties during this global crisis. Third, the COVID-19 pandemic has been associated with significant job loss and associated financial strain, which may contribute to increased rates of anxiety and depression, particularly among mothers of young children. Indeed, past research has found that financial strain was a significant predictor of reduced mental health among mothers (Black et al., 2009; Crosier et al., 2007). Taken together, increased maternal mental health difficulties during the pandemic may be largely attributable to decreases in support at the family level and increased stress due to financial stain.

Across meta-analyses, we found that the prevalence of maternal depression and anxiety increased with age, whereby older mothers reported the greatest symptom burden. In addition, reports of clinically elevated anxiety were higher among mothers with versus without a university education. Although maternal maturity and education may be protective in the context of the family environment (e.g., parenting skills; (Bornstein et al., 2006), researchers have 
emphasized that delayed parenting may come with time-associated biological costs for maternal mental health (McMahon et al., 2015). For example, maternal age is associated with increased risk for adverse pregnancy outcomes (Lean et al., 2017) and, in turn, older mothers may experience greater anxiety and depression in the perinatal period (Garcia-Blanco et al., 2017). With the added physical threat of COVID-19 infection and the pandemic's associated impact on maternal access to social supports, it is likely that mental health difficulties among older mothers may have been triggered or exacerbated by COVID-19-related stressors. In addition, studies have indicated that older versus younger mothers often have higher levels of education, consequently, hold job positions with greater levels of responsibility and income (Bouchard et al., 2008; McMahon et al., 2015). At the same time, older versus younger mothers also balance greater levels of family responsibility (Garcia-Blanco et al., 2017). Thus, closure of schools and daycares, shifts to at-home work, and loss of income may have significantly affected older and more educated mothers who provide incomes for their families. Future research on the impact of work status on maternal mental health during the pandemic is needed to clarify the relation between maternal age, education level, and anxiety and depression. Nonetheless, efforts to alleviate mental health concerns among older and highly educated mothers should focus on enhancing natural social supports (e.g., partner support) and providing tangible supports (e.g., increased paid time off, flexible work schedules) to offset the demands exacerbated by COVID19.

Counter to our hypotheses that racial and ethnic minority mothers would experience higher levels of mental health difficulties during the COVID-19 pandemic, we found that studies with a higher proportion minoritized mothers had lower reported prevalence rates of depressive symptoms. These findings are counter to previous studies documenting the disproportionate 
impact of COVID-19 on historically oppressed communities (Hooper, 2020), particularly as it relates to elevated mortality rates as well as reduced access to social determinants of health during the COVID-19 pandemic (e.g., access to safe housing, health care, food insecurity)(Brown et al., 2020; Hooper, 2020; McKnight-Eily et al., 2021). Although few studies have examined the role of race and ethnicity on mental health outcomes in parents during the pandemic, Brown et al. (2020) found that Latinx parents in the United States reported the highest number of COVID-19 related stressors. One explanation for our disparate finding in the current study may have to do with racial and ethnic minority mothers being more likely to be employed as essential or healthcare workers. A large population-based study in the UK found that participants who were essential works were less likely to experience severe depressive symptoms during the pandemic (Iob et al., 2020). Furthermore, belonging to a racial or ethnic minority group was not associated with experiencing severe depressive symptoms during the pandemic (Iob et al., 2020). Research in mothers of middle school children during the COVID-19 pandemic has also shown a protective effect among racial and ethnic minority mothers as compared to white mothers for anxiety symptoms (Racine et al., 2021). Taken together, more research is needed to disentangle what might be contributing to the potential resilience among racialized mothers with regards to mental health difficulties during the pandemic.

Moderator analyses identified that rates of anxiety and depression were highest among mothers in North American and European countries, in comparison to South American, Middle Eastern, South East Asian, and South Asian counties. These findings may reflect the relatively higher rates of COVID-19 cases and deaths found in North America and Europe at the outset of the pandemic (WHO, 2021) and potentially greater associated consequences of the pandemic, including reduced social contact, economic hardship, home confinement, and grief, that may 
initiate or exacerbate mental health concerns. Thus, policy makers and public health officials in these regions should identify avenues to provide funding and support for evidence-based mental health screening and treatment among mothers. In addition, the prevalence of anxiety was higher in studies of lower versus methodological quality, a finding that has been shown in other metaanalysis on adult mental health during COVID-19 (e.g., (Cooke et al., 2020). It may be that methodological quality was sacrificed due to the need to rapidly conduct research at the beginning of the pandemic. Future studies with greater methodological rigor are needed to ensure prevalence rates of maternal anxiety are not overestimated.

\subsection{Limitations}

The findings of the current meta-analysis should be considered with certain limitations in mind. The first and most important limitation of this study was the lack of reports on fathers' mental health during COVID-19. The involvement of fathers has increased considerably over the past few decades (Yogman et al., 2016). Therefore, it cannot be understated how crucial it is to also assess how fathers are also coping during and beyond the pandemic. Several studies also failed to report on and include ethnic and socioeconomic diverse participants in their studies. With less than $30 \%$ of participants identifying as minority and most mothers having good education and marital partners, the results may not generalize outside of populations with low known social risks. We are also limited in our ability to make similar conclusions about mothers in higher risk samples who may be more susceptible to higher rates of anxiety and depression (Alonzo et al., 2021). Given that the average age of children in the study was less than 1 year old, future work is needed to understand the mental health impact of the COVID-19 pandemic on mothers of older children and adolescents. A previous study has demonstrated the decline of parenting stress across early childhood (Williford et al., 2007). However, with the closures of 
schools and other support programs, dealing with school-aged child during COVID presents its own unique challenges which may exacerbate the distress that mothers experience (see (Racine et al., 2021). A further limitation of the study was the lack of representative and populationrepresentative samples, which should be prioritized in future research (Pierce, McManus, et al., 2020).

\section{Conclusion, Implications and Directions for Future Research}

Findings from the current meta-analysis highlight pressing concerns about the mental wellbeing of mothers of young children during the COVID-19 pandemic. Mental health concerns were greatest among mothers who were older, highly educated, from racial or ethnic majority group, and living in North American or European regions. Results underscore the need to dedicate significant resources toward addressing mental health concerns among mothers. At the individual level, the rapid implementation of brief, psychometrically-sound screening instruments (e.g., PHQ-2, GAD-2; (Staples et al., 2019) in perinatal and pediatric primary care settings may serve as a feasible avenue to identify mothers at risk of depression and anxiety. Moreover, the development of brief, evidence-based interventions for parental distress that can be delivered via telemental health and in group contexts may help to reach a wider audience of mothers and reduce potential barriers to care. At the familial level, resources must also be dedicated to mitigating the potential negative effects of maternal depression and anxiety on child developmental outcomes. This may include mobilizing evidence-based parenting programs to mothers with identified mental health concerns and providing early intervention for offspring with identified concerns. Finally, at the systemic level, researchers have emphasized the need for government bodies and policymakers to invest in and expand social services (e.g., stable housing, childcare), map and coordinate existing social and mental health services for families, 
provide targeted outreach to populations at greatest risk, and change policies that sustain and promote discrimination (Fontanesi et al., 2020; Goldman et al., 2020; Shim, 2020). Altogether, these efforts may help to address the concerning prevalence of depression and anxiety among mothers during COVID-19.

In terms of areas for future research, studies are needed on the mental health implications of COVID-19 for fathers. Emerging studies have indicated a shift in the division of family and household responsibilities at the onset of the pandemic, whereby fathers' level of involvement has increased (Mangiavacchi et al., 2020; Shafer et al., 2020). However, it is unclear whether this shift in labor has had implications for fathers' parenting stress or other areas of mental health. In line with this aim, investigations on the role of partner support and marital conflict with respect to parent mental health may help shed light on the relationship characteristics that may buffer or worsen depression and anxiety in the context of COVID-19. Further research is also needed on mothers with pre-existing physical and mental health conditions, as well as mothers of children with mental, developmental, or physical concerns, where parenting stress and mental illness may be heightened. Finally, multigenerational, longitudinal research is greatly needed to determine if the high rates of maternal depression and anxiety identified at present are reflective of an acute period of distress or sustained effects of COVID-19 with enduring consequences for child wellbeing as well.

Conflicts of interest: The authors have no conflict of interest to declare.

Data availability: Data were extracted from published studies. Extracted data, study protocols, and analyses will be shared as requested from the corresponding author. 
Table 1

Characteristics of Studies Included

\begin{tabular}{|c|c|c|c|c|c|c|c|c|c|c|}
\hline $\begin{array}{l}\text { First Author, } \\
\text { Year, } \\
\text { Reference }\end{array}$ & $\mathbf{N}^{\mathbf{a}}$ & $\begin{array}{l}\text { Maternal } \\
\text { Age } \\
\text { (years) }\end{array}$ & $\begin{array}{l}\text { Child } \\
\text { Age } \\
\text { (months) }\end{array}$ & $\begin{array}{l}\text { \% } \\
\text { Minority }\end{array}$ & $\begin{array}{l}\text { \% } \\
\text { University } \\
\text { Educated }\end{array}$ & $\begin{array}{l}\% \\
\text { Married }\end{array}$ & Country & $\begin{array}{l}\text { Mental } \\
\text { Health } \\
\text { Measured }\end{array}$ & $\begin{array}{l}\text { Name of } \\
\text { Mental Health } \\
\text { Measures }\end{array}$ & Data Collection Date \\
\hline Cameron 2020 & 475 & 34.27 & $0-60$ & 16.17 & 71.4 & 91.5 & Canada & Anx, Dep & $\begin{array}{l}\text { PASS, EPDS, } \\
\text { GAD-7, }\end{array}$ & Apr $14-28,2020$ \\
\hline Chaves 2021 & 724 & 33.36 & & - & 76.4 & 91.4 & Spain & Anx, Dep & $\begin{array}{l}\text { EPDS: items } \\
3,4,5, \text { EPDS }\end{array}$ & Apr 7th-May 8th, 2020 \\
\hline Fallon 2021 & 614 & 30.9 & 1.75 & 4.1 & 21.50 & 57 & $\begin{array}{l}\text { United } \\
\text { Kingdom }\end{array}$ & Anx, Dep & STAI-S, EPDS & Apr 16 to May 15, 2020 \\
\hline $\begin{array}{l}\text { Hamadani } \\
2020\end{array}$ & 2410 & 24.1 & 18.2 & & 3.6 & & Bangladesh & Anx & GAD-7 & $\begin{array}{l}\text { May } 19 \text { to June } 18 \text {, } \\
2020\end{array}$ \\
\hline Harrison 2021 & 201 & 32.2 & 6.29 & 5.2 & 72.1 & 97.2 & UK & Anx, Dep & PASS, EPDS & May-June, 2020 \\
\hline $\begin{array}{l}\text { LoretdeMola } \\
2021\end{array}$ & 591 & & $<12$ & - & & & Brazil & Anx, Dep & GAD-7, EPDS & July-Dec 2020 \\
\hline Molgora 2020 & $\begin{array}{l}170 \\
\text { (anx), } \\
186 \\
\text { (dep) }\end{array}$ & 33.01 & $<6$ & - & 66.6 & & Italy & Anx, Dep & STAI, EPDS & Mar 1-May 3, 2020 \\
\hline $\begin{array}{l}\text { Oskovi-Kaplan } \\
2020\end{array}$ & 223 & 26.15 & 0.07 & & & & Turkey & Dep & EPDS & June 2020 \\
\hline Ostacoli 2020 & 163 & 34.77 & $<4$ & 4.9 & 61.3 & 93.30 & Italy & Dep & EPDS & June 15 - 29, 2020 \\
\hline Pariente 2020 & 223 & 29.1 & 0.07 & 46.6 & & 90.60 & Israel & Dep & EPDS & Mar 18-April 29, 2020 \\
\hline $\begin{array}{l}\text { Silverman } \\
2020\end{array}$ & 252 & 27 & $<12$ & 90 & & & United States & Dep & EPDS & Jan 2-June 30, 2020 \\
\hline Spinola 2020 & 243 & 34.01 & 3.78 & & 80.94 & 93.44 & Italy & Dep & EPDS & May 11 to June 6,2020 \\
\hline Stojanov 2020 & 108 & 32 & $<12$ & & 70.9 & 87 & Serbia & Dep & EPDS & $\begin{array}{l}\text { Mar 29th to Apr 4th, } \\
2020\end{array}$ \\
\hline Suhariati 2020 & 51 & $20-34$ & 60 & - & 19.6 & - & Indonesia & Anx & Zung SAS & Sept 2020 \\
\hline Sun 2020 & 2092 & $\begin{array}{l}41.42 \% \\
\text { aged } 25- \\
29\end{array}$ & & 2.8 & 79.01 & - & China & Dep & EPDS & $\begin{array}{l}\text { Dec 31, } 2019 \text { - Mar 22, } \\
2020\end{array}$ \\
\hline Suzuki 2020 & 132 & $\begin{array}{l}79.6 \% \\
\text { aged } 19- \\
40\end{array}$ & 1 & - & - & - & Japan & Dep & EPDS & Mar 11 - April 13, 2020 \\
\hline Zanardo 2020 & 91 & 33.73 & $<1$ & - & - & 57.1 & Italy & Dep & EPDS & Mar 8 - May 3, 2020 \\
\hline
\end{tabular}


Note: Anx: Anxiety; CESD: Centre for Epidemiologic Studies Depression Scale; CESD-R: Centre for Epidemiologic Studies Depression Scale Revised; Dep: Depression ; EPDS: Edinburgh Postnatal Depression Scale; GAD-7: Generalized Anxiety Disorder 7-Item; PASS: Perinatal Anxiety Screening Scale; STAI: Spielberger State Trait Anxiety Inventory; STAI: Spielberger State Trait Anxiety Inventory, State Scale; Zung SAS: Zung Self-Rating Anxiety Scale.

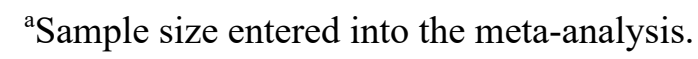


Table 2: Results of moderator analyses for the prevalence of clinically elevated depressive symptoms in mothers of young children during COVID-19

\begin{tabular}{|c|c|c|c|c|c|}
\hline Categorical Moderators & $\mathbf{k}$ & Prevalence & $95 \% \mathrm{CI}$ & Homogeneity $Q$ & $p$ \\
\hline Study Quality Score & & & & 0.712 & .399 \\
\hline Low (2-3) & 10 & $.297 * *$ & $.217, .391$ & & \\
\hline High (4) & 6 & $.239^{* * *}$ & $.155, .350$ & & \\
\hline Geographical Region & & & & 4.25 & .04 \\
\hline $\begin{array}{l}\text { South America, Middle } \\
\text { East, Asia }\end{array}$ & 5 & $.185^{* * *}$ & $.112, .289$ & & \\
\hline Europe/North America & 11 & $.322^{* * *}$ & $.243, .414$ & & \\
\hline Continuous Moderators & $\mathbf{k}$ & Estimate & & $Z$ & $p$ \\
\hline Maternal age & 14 & .185 & & 2.47 & .01 \\
\hline Child age & 13 & .03 & $.04, .09$ & .75 & .45 \\
\hline Month of data collection in 2020 & 16 & .08 & $-.13, .30$ & .75 & .45 \\
\hline Maternal education & 10 & .01 & $-.004,0.03$ & 1.44 & .15 \\
\hline Ethnic minority status & 8 & -03 & $-.04,-.02$ & -5.12 & $<.001$ \\
\hline Marital status & 9 & .02 & $-.001,0.04$ & 1.84 & .07 \\
\hline
\end{tabular}


Table 3: Results of moderator analyses for the prevalence of clinically elevated anxiety symptoms in mothers of young children during COVID-19.

\begin{tabular}{|c|c|c|c|c|c|}
\hline Categorical Moderators & $\mathbf{k}$ & Prevalence & $95 \%$ CI & Homogeneity $Q$ & $p$ \\
\hline Study Quality Score & & & & 11.98 & .001 \\
\hline Low (scores of 2-3) & 6 & $.297 * *$ & $.421, .634$ & & \\
\hline High (score of 4) & 2 & $.200^{* * *}$ & $.107, .342$ & & \\
\hline Geographical Region & & & & 5.99 & .01 \\
\hline $\begin{array}{l}\text { South America, Middle } \\
\text { East, Asia }\end{array}$ & 3 & $.279^{* * *}$ & $.164, .433$ & & \\
\hline Europe/North America & 5 & $.529^{* * *}$ & $.401, .652$ & & \\
\hline Continuous Moderators $^{\mathrm{a}}$ & $\mathbf{k}$ & Estimate & $95 \% \mathrm{CI}$ & $Z$ & $p$ \\
\hline Maternal age & 6 & .18 & & 2.01 & .04 \\
\hline Child age & 7 & .006 & & .28 & .78 \\
\hline Month of data collection in 2020 & 8 & -.08 & $-.43, .25$ & -.50 & .61 \\
\hline Maternal education & 6 & .02 & $.003,0.04$ & 2.27 & .02 \\
\hline Marital status & 5 & -.01 & $-.03,0.01$ & -0.86 & .39 \\
\hline
\end{tabular}

Note. $\mathrm{k}=$ number of studies; $\mathrm{CI}=$ confidence interval. ${ }^{*} p<.05 ;{ }^{* *} p<.01 ;{ }^{* * *} p<.001$. ${ }^{\mathrm{a}}$ There were insufficient studies to examine ethnic minority status as a moderator. 
Figure 1: PRISMA flow diagram.
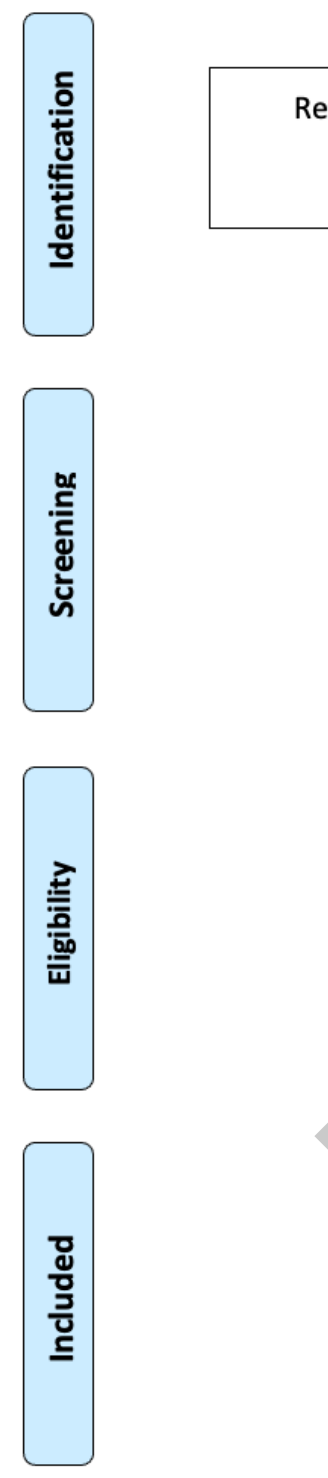
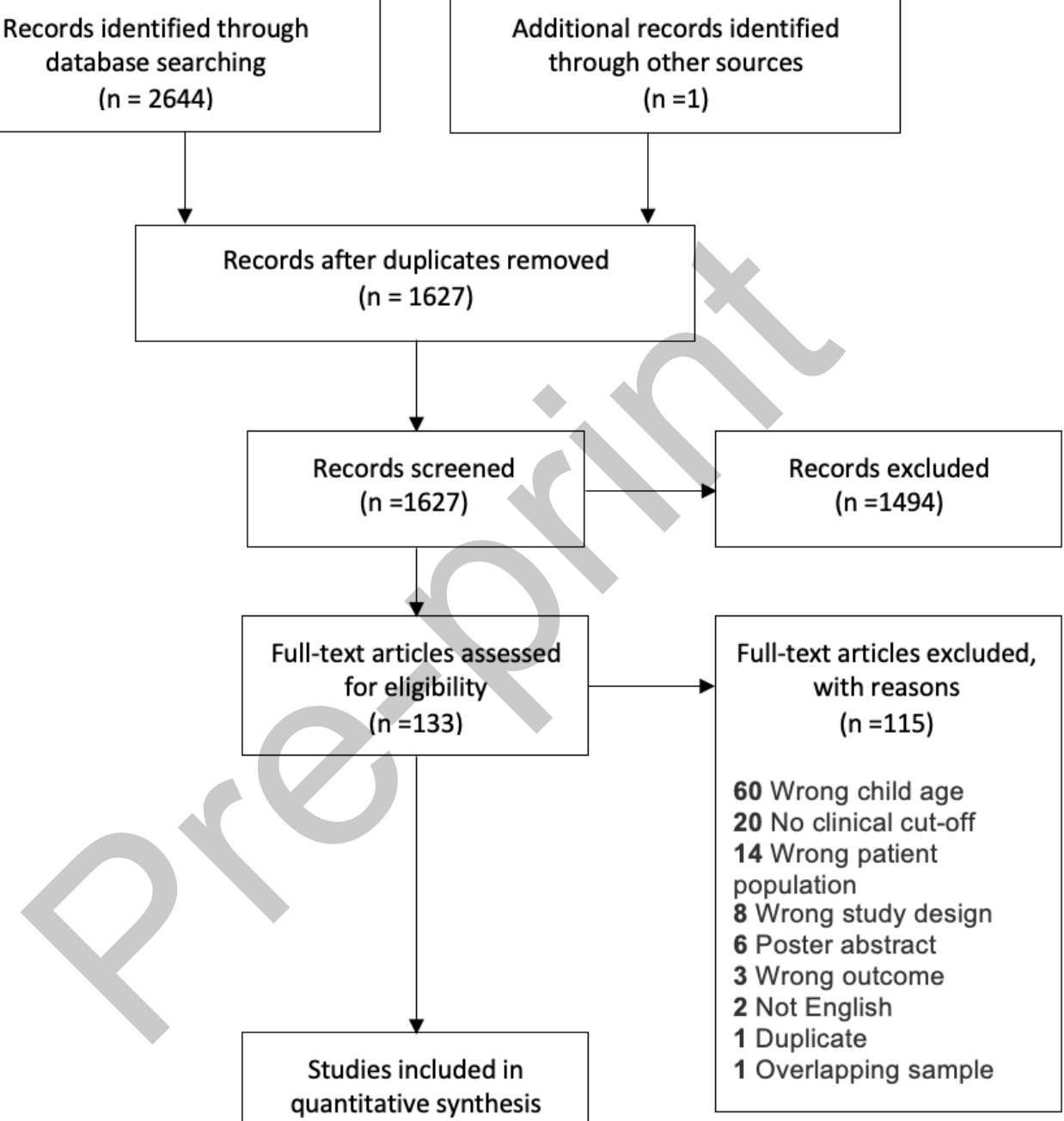

(meta-analysis)

$$
(n=18)
$$


Figure 2: Forest plots of the pooled prevalence of clinically elevated depressive and anxiety symptoms in mothers of young children during the COVID-19 pandemic.

\section{Study}

\section{Anxiety}

Cameron 2020

Chaves 2021

Fallon 2021

Harrison 2021

LoretdeMola 2021

Molgora 2020

Oskovi-Kaplan 2020

Ostacoli 2020

Total

\section{Depression}

Pariente 2020

Silverman 2020

Spinola 2020

Stojanov 2020

Sun 2020

Suzuki 2020

Zanardo 2020

Zanardo 2021

Cameron 2020

Chaves 2021

Fallon 2021

Hamadani 2020

Harrison 2021

LoretdeMola 2021

Molgora 2020

Suhariati 2020

Total

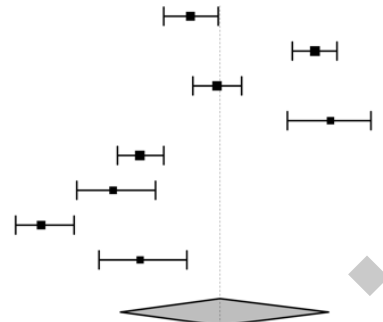

$1-1$

$1+-1$
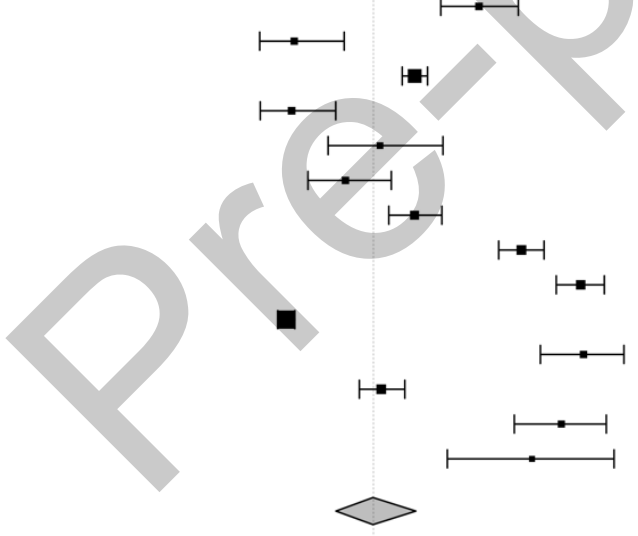

te-1

Rate $[95 \% \mathrm{Cl}]$

\section{Rate $[95 \% \mathrm{Cl}]$}

$0.39[0.34,0.43]$

$0.59[0.55,0.62]$

$0.43[0.39,0.47]$

$0.61[0.54,0.68]$

$0.31[0.27,0.34]$

$0.26[0.21,0.33]$

$0.15[0.11,0.20]$

$0.31[0.24,0.38]$

$0.43[0.28,0.61]$

$0.07[0.04,0.11]$

$0.06[0.04,0.10]$

$0.44[0.38,0.51]$

$0.15[0.09,0.23]$

$0.34[0.32,0.36]$

$0.14[0.09,0.21]$

$0.29[0.20,0.39]$

$0.23[0.17,0.30]$

$0.34[0.30,0.38]$

$0.51[0.48,0.55]$

$0.61[0.57,0.65]$

$0.13[0.12,0.15]$

0.61 [0.54, 0.68]

$0.29[0.25,0.33]$

$0.58[0.50,0.65]$

$0.53[0.39,0.66]$

$0.27[0.22,0.34]$

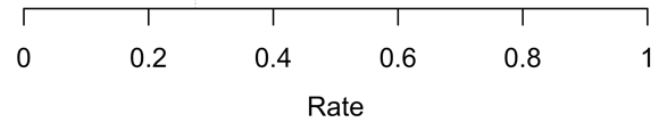




\section{References}

Abdullah, T., \& Brown, T. L. (2011). Mental illness stigma and ethnocultural beliefs, values, and norms: an integrative review. Clin Psychol Rev, 31(6), 934-948.

https://doi.org/10.1016/j.cpr.2011.05.003

Alonzo, D., Popescu, M., \& Zubaroglu Ioannides, P. (2021). Mental health impact of the Covid-19 pandemic on parents in high-risk, low income communities. Int J Soc Psychiatry, 20764021991896. https://doi.org/10.1177/0020764021991896

Anderson, N. J., Graham, S. A., Prime, H., Jenkins, J. M., \& Madigan, S. (2021). Linking Quality and Quantity of Parental Linguistic Input to Child Language Skills: A Meta-Analysis. Child Development, 92(2), 484-501. https://doi.org/https://doi.org/10.1111/cdev.13508

Badovinac, S., Martin, J., Guérin-Marion, C., O’Neill, M., Pillai Riddell, R., Bureau, J.-F., \& Spiegel, R. (2018). Associations between mother-preschooler attachment and maternal depression symptoms: A systematic review and meta-analysis. PloS one, 13(10), e0204374. https://doi.org/https://doi.org/10.1371/journal.pone.0204374

Barnes, J., \& Theule, J. (2019). Maternal depression and infant attachment security: A meta-analysis. Infant Mental Health Journal, 40(6), 817-834. https://doi.org/https://doi.org/10.1002/imhj.21812

Bernard, K., Nissim, G., Vaccaro, S., Harris, J. L., \& Lindhiem, O. (2018). Association between maternal depression and maternal sensitivity from birth to 12 months: a meta-analysis. Attachment \& Human Development, 20(6), 578-599. https://doi.org/10.1080/14616734.2018.1430839

Black, A. R., Murry, V. M., Cutrona, C. E., \& Chen, Y. F. (2009). Multiple roles, multiple lives: the protective effects of role responsibilities on the health functioning of African American mothers. Women Health, 49(2-3), 144-163. https://doi.org/10.1080/03630240902915051

Borenstein, M., Hedges, L., Higgins, J., \& Rothstein, H. (2013). Comprehensive Meta-Analysis Version 3. In Biostat. 
Borenstein, M., Hedges, L. V., Higgins, J. P., \& Rothstein, H. R. (2010). A basic introduction to fixedeffect and random-effects models for meta-analysis. Res Synth Methods, 1(2), 97-111. https://doi.org/10.1002/jrsm.12

Borenstein, M., Hesdges, L., Higgins, J., \& Rothstein, H. (2009). Introduction to Meta-Analysis. Wiley.

Bornstein, M. H., Putnick, D. L., Suwalsky, J. T., \& Gini, M. (2006). Maternal chronological age, prenatal and perinatal history, social support, and parenting of infants. Child Dev, 77(4), 875-892. https://doi.org/10.1111/j.1467-8624.2006.00908.x

Bouchard, G., Lachance-Grrzela, M., \& Goguen, A. (2008). Timing of the transition to motherhood and union quality: The moderartor role of union length. Personal relationships, 15(1), 71-80.

Brown, S. M., Doom, J. R., Lechuga-Pena, S., Watamura, S. E., \& Koppels, T. (2020). Stress and parenting during the global COVID-19 pandemic. Child Abuse Negl, 110 (Pt 2), 104699. https://doi.org/10.1016/j.chiabu.2020.104699

Bullock, L. F., Browning, C., \& Geden, E. (2002). Telephone social support for low-income pregnant women. J Obstet Gynecol Neonatal Nurs, 31(6), 658-664. https://www.ncbi.nlm.nih.gov/pubmed/12465861

Calarco, J. M., Anderson, E. M., Meanwell, E. V., \& Knopf, A. (2020 ). “Let's Not Pretend It’s Fun”: How COVID-19-Related School and Childcare Closures are Damaging Mothers' Well-Being. https://doi.org/https://doi.org/10.31235/osf.io/jyvk4

Cameron, E. E., Joyce, K. M., Delaquis, C. P., Reynolds, K., Protudjer, J. L. P., \& Roos, L. E. (2020). Maternal psychological distress \& mental health service use during the COVID-19 pandemic. $J$ Affect Disord, 276, 765-774. https://doi.org/10.1016/j.jad.2020.07.081

Cameron, E. E., Sedov, I. D., \& Tomfohr-Madsen, L. M. (2016). Prevalence of paternal depression in pregnancy and the postpartum: An updated meta-analysis. J Affect Disord, 206, 189-203. https://doi.org/10.1016/j.jad.2016.07.044

Carlson, D. L., Petts, R., \& Pepin, J. R. (2020). Changes in Parents' Domestic Labor During the COVID19 Pandemic. 
Chaves, C., Marchena, C., Palacios, B., Salgado, A., \& Duque, A. (2021). Effects of the COVID-19 pandemic on perinatal mental health in Spain: Positive and negative outcomes. Women Birth. https://doi.org/10.1016/j.wombi.2021.01.007

Cheng, Z., Mendolia, S., Paloyo, A. R., Savage, D. A., \& Tani, M. (2021). Working parents, financial insecurity, and childcare: mental health in the time of COVID-19 in the UK. Rev Econ Househ, 122. https://doi.org/10.1007/s11150-020-09538-3

Cobham, V. E., \& McDermott, B. (2014). Perceived parenting change and child posttraumatic stress following a natural disaster. J Child Adolesc Psychopharmacol, 24(1), 18-23. https://doi.org/10.1089/cap.2013.0051

Collins, C., Landivar, L. C., Ruppanner, L., \& Scarborough, W. J. (2020). COVID-19 and the Gender Gap in Work Hours. Gend Work Organ. https://doi.org/10.1111/gwao.12506

Cooke, J. E., Eirich, R., Racine, N., \& Madigan, S. (2020). Prevalence of posttraumatic and general psychological stress during COVID-19: A rapid review and meta-analysis. Psychiatry Research, 292, 113347. https://doi.org/https://doi.org/10.1016/j.psychres.2020.113347

Crosier, T., Butterworth, P., \& Rodgers, B. (2007). Mental health problems among single and partnered mothers. The role of financial hardship and social support. Soc Psychiatry Psychiatr Epidemiol, 42(1), 6-13. https://doi.org/10.1007/s00127-006-0125-4

De Wolff, M., \& van Ijzendoorn, M. (1997). Sensitivity and Attachment: A Meta-Analysis on Parental Antecedents of Infant Attachment. Child Development, 68(4), 571-591. https://doi.org/https://doi.org/10.1111/j.1467-8624.1997.tb04218.x

Dennis, C. L., Falah-Hassani, K., \& Shiri, R. (2017). Prevalence of antenatal and postnatal anxiety: systematic review and meta-analysis. Br J Psychiatry, 210(5), 315-323. https://doi.org/10.1192/bjp.bp.116.187179

Dias, F. A., Chance, J., \& Buchanan, A. (2020). The motherhood penalty and The fatherhood premium in employment during covid-19: evidence from The united states. Res Soc Stratif Mobil, 69, 100542. https://doi.org/10.1016/j.rssm.2020.100542 
Duval, S., \& Tweedie, R. (2004). Trim and fill: A simple funnel-plot based method of testing and adjusting for publication bias in meta-analysis. Biometrics, 56(2), 455-463.

Egger, M., Davey, G., Schneider, M., \& Minder, C. (1997). Bias in meta-analysis detected by a simple, graphical test. $B M J, 315(7109), 629-634$.

Etowa, J., \& Hyman, I. (2021). Unpacking the health and social consequences of COVID-19 through a race, migration and gender lens. Can J Public Health, 112(1), 8-11. https://doi.org/10.17269/s41997-020-00456-6

Fallon, V., Davies, S. M., Silverio, S. A., Jackson, L., De Pascalis, L., \& Harrold, J. A. (2021). Psychosocial experiences of postnatal women during the COVID-19 pandemic. A UK-wide study of prevalence rates and risk factors for clinically relevant depression and anxiety. J Psychiatr Res, 136, 157-166. https://doi.org/10.1016/j.jpsychires.2021.01.048

Field, T. (2010). Postpartum depression effects on early interactions, parenting, and safety practices: A review. Infant Behavior and Development, 33(1), 1-6. https://doi.org/https://doi.org/10.1016/j.infbeh.2009.10.005

Fontanesi, L., Marchetti, D., Mazza, C., Di Giandomenico, S., Roma, P., \& Verrocchio, M. C. (2020). The effect of the COVID-19 lockdown on parents: A call to adopt urgent measures. . Psychological Trauma: Theory, Research, Practice, and Policy,, 12, S79-S81. https://doi.org/http://dx.doi.org/10.1037/tra0000672

Garcia-Blanco, A., Monferrer, A., Grimaldos, J., Hervas, D., Balanza-Martinez, V., Diago, V., Vento, M., \& Chafer-Pericas, C. (2017). A preliminary study to assess the impact of maternal age on stressrelated variables in healthy nulliparous women. Psychoneuroendocrinology, 78, 97-104. https://doi.org/10.1016/j.psyneuen.2017.01.018

Gelfand, D., \& Teti, D. (1990). The effects of maternral depression on children. Clinical Psychology Review, 10(3), 329-353.

Goldman, M. L., Druss, B. G., Horvitz-Lennon, M., Norquist, G. S., Kroeger Ptakowski, K., Brinkley, A., Greiner, M., Hayes, H., Hepburn, B., Jorgensen, S., Swartz, M. S., \& Dixon, L. B. (2020). Mental 
Health Policy in the Era of COVID-19. Psychiatr Serv, 71(11), 1158-1162.

https://doi.org/10.1176/appi.ps.202000219

Goldman-Mellor, S., Saxton, K., \& Catalano, R. (2014). Economic contraction and mental health: A review of the evidence, 1990-2009. International Journal of Mental Health, 39(2), 6-31.

Goodman, S. H., Rouse, M. H., Connell, A. M., Broth, M. R., Hall, C. M., \& Heyward, D. (2011). Maternal depression and child psychopathology: a meta-analytic review. Clin Child Fam Psychol Rev, 14(1), 1-27. https://doi.org/10.1007/s10567-010-0080-1

Hamadani, J. D., Hasan, M. I., Baldi, A. J., Hossain, S. J., Shiraji, S., Bhuiyan, M. S. A., Mehrin, S. F., Fisher, J., Tofail, F., Tipu, S., Grantham-McGregor, S., Biggs, B. A., Braat, S., \& Pasricha, S. R. (2020). Immediate impact of stay-at-home orders to control COVID-19 transmission on socioeconomic conditions, food insecurity, mental health, and intimate partner violence in Bangladeshi women and their families: an interrupted time series. Lancet Glob Health, 8(11), e1380-e1389. https://doi.org/10.1016/S2214-109X(20)30366-1

Harrison, V., Moulds, M. L., \& Jones, K. (2021). Support from friends moderates the relationship between repetitive negative thinking and postnatal wellbeing during COVID-19. J Reprod Infant Psychol, 1-16. https://doi.org/10.1080/02646838.2021.1886260

Hentges, R., Graham, S., Plamondon, A., Tough, S., \& Madigan, S. (2021). Bidirectional associations between mateernal depression, hostile parreneting, and early child emotional problems: FIndings frorm the All Our Families cohort. Journal of Affective Disorders.

Hertz, R., Mattes, J., \& Shook, A. (2020). When Paid Work Invades the Family: Single Mothers in the COVID-19 Pandemic. . Journal of Family Issues. https://doi.org/10.1177/0192513X20961420

Hetherington, E., McDonald, S., Williamson, T., Patten, S. B., \& Tough, S. C. (2018). Social support and maternal mental health at 4 months and 1 year postpartum: analysis from the All Our Families cohort. J Epidemiol Community Health, 72(10), 933-939. https://doi.org/10.1136/jech-2017$\underline{210274}$ 
Hjalmsdottir, A., \& Bjarnadottir, V. S. (2020). "I have turned into a foreman here at home." Families and work-life balance in times of Covid-19 in a gender equality paradise. Gend Work Organ. https://doi.org/10.1111/gwao.12552

Hooper, M., Napoles, A., Perez-Stable, E. (2020). COVID-19 and racial/ethnic disparities. JAMA, $323(24), 2466-2467$.

Horne, R. M., Johnson, M. D., Galambos, N. L., \& Krahn, H. J. (2018). Time, money, or gender? Predictors of the division of household labour across life stages. . Sex Roles, 78(11), 731-743.

Horwitz, S. M., Briggs-Gowan, M. J., Storfer-Isser, A., \& Carter, A. S. (2007). Prevalence, correlates, and persistence of maternal depression. J Womens Health (Larchmt), 16(5), 678-691. https://doi.org/10.1089/jwh.2006.0185

Howard, L. M., Molyneaux, E., Dennis, C. L., Rochat, T., Stein, A., \& Milgrom, J. (2014). Non-psychotic mental disorders in the perinatal period. Lancet, 384(9956), 1775-1788. https://doi.org/10.1016/S0140-6736(14)61276-9

Iob, E., Frank, P., Steptoe, A., \& Fancourt, D. (2020). Levels of Severity of Depressive Symptoms Among At-Risk Groups in the UK During the COVID-19 Pandemic. JAMA Netw Open, 3(10), e2026064. https://doi.org/10.1001/jamanetworkopen.2020.26064

Lean, S. C., Derricott, H., Jones, R. L., \& Heazell, A. E. P. (2017). Advanced maternal age and adverse pregnancy outcomes: A systematic review and meta-analysis. PloS one, 12(10), e0186287. https://doi.org/10.1371/journal.pone.0186287

Lee, J. (2020). Mental health effects of school closures during COVID-19. Lancet Child Adolesc Health, 4(6), 421. https://doi.org/10.1016/S2352-4642(20)30109-7

Loret de Mola, C., Blumenberg, C., Martins, R. C., Martins-Silva, T., Carpena, M. X., Del-Ponte, B., Pearson, R., Soares, A. L., \& Cesar, J. A. (2021). Increased depression and anxiety during the COVID-19 pandemic in Brazilian mothers: a longitudinal study. Braz J Psychiatry. https://doi.org/10.1590/1516-4446-2020-1628 
Lovejoy, M. C., Graczyk, P. A., O'Hare, E., \& Neuman, G. (2000). Maternal depression and parenting behavior: a meta-analytic review. Clin Psychol Rev, 20(5), 561-592. https://doi.org/10.1016/s0272-7358(98)00100-7

Lyons-Ruth, K., Lyubchik, A., Wolfe, R., \& Bronfman, E. (2002). Parental depression and child attachment: Hostile and helpless profiles of parent and child behavior among families at risk. . In S. H. G. I. H. Gotlib (Ed.), Children of depressed parents: Mechanisms of risk and implications for treatment (pp. p. 89-120). American Psychological Association. https://doi.org/ https://doi.org/10.1037/10449-004

Mangiavacchi, L., Piccoli, L., \& Pieroni, L. (2020). Fathers Matter: Intra-Household Responsibilities and Children's Wellbeing during the COVID-19 Lockdown in Italy, IZA, Discussion Papers, No. 13519.

Mathiesen, K. S., Tambs, K., \& Dalgard, O. S. (1999). The influence of social class, strain and social support on symptoms of anxiety and depression in mothers of toddlers. Soc Psychiatry Psychiatr Epidemiol, 34(2), 61-72. https://doi.org/10.1007/s001270050113

McKnight-Eily, L. R., Okoro, C. A., Strine, T. W., Verlenden, J., Hollis, N. D., Njai, R., Mitchell, E. W., Board, A., Puddy, R., \& Thomas, C. (2021). Racial and Ethnic Disparities in the Prevalence of Stress and Worry, Mental Health Conditions, and Increased Substance Use Among Adults During the COVID-19 Pandemic - United States, April and May 2020. MMWR Morb Mortal Wkly Rep, 70(5), 162-166. https://doi.org/10.15585/mmwr.mm7005a3

McMahon, C. A., Boivin, J., Gibson, F. L., Hammarberg, K., Wynter, K., \& Fisher, J. R. (2015). Older maternal age and major depressive episodes in the first two years after birth: findings from the Parental Age and Transition to Parenthood Australia (PATPA) study. J Affect Disord, 175, 454462. https://doi.org/10.1016/j.jad.2015.01.025

Moher, D., Liberati, A., Tetzlaff, J., Altman, D. G., \& Group, P. (2009). Preferred reporting items for systematic reviews and meta-analyses: the PRISMA statement. PLoS Med, 6(7), e1000097. https://doi.org/10.1371/journal.pmed.1000097 
Molgora, S., \& Accordini, M. (2020). Motherhood in the Time of Coronavirus: The Impact of the Pandemic Emergency on Expectant and Postpartum Women's Psychological Well-Being. Front Psychol, 11, 567155. https://doi.org/10.3389/fpsyg.2020.567155

National Heart, L., \& Blood, I. (2014). Quality assessment tool for observational cohort and crosssectional studies.

O'Connor, R. C., Wetherall, K., Cleare, S., McClelland, H., Melson, A. J., Niedzwiedz, C. L., O'Carroll, R. E., O'Connor, D. B., Platt, S., Scowcroft, E., Watson, B., Zortea, T., Ferguson, E., \& Robb, K. A. (2020). Mental health and well-being during the COVID-19 pandemic: longitudinal analyses of adults in the UK COVID-19 Mental Health \& Wellbeing study. Br J Psychiatry, 1-8. https://doi.org/10.1192/bjp.2020.212

Ollivier, R., Aston, D. M., Price, D. S., Sim, D. M., Benoit, D. B., Joy, D. P., Iduye, D., \& Nassaji, N. A. (2021). Mental Health \& Parental Concerns during COVID-19: The Experiences of New Mothers Amidst Social Isolation. Midwifery, 94, 102902. https://doi.org/10.1016/j.midw.2020.102902

Oskovi-Kaplan, Z. A., Buyuk, G. N., Ozgu-Erdinc, A. S., Keskin, H. L., Ozbas, A., \& Moraloglu Tekin, O. (2020). The Effect of COVID-19 Pandemic and Social Restrictions on Depression Rates and Maternal Attachment in Immediate Postpartum Women: a Preliminary Study. Psychiatr Q. https://doi.org/10.1007/s11126-020-09843-1

Ostacoli, L., Cosma, S., Bevilacqua, F., Berchialla, P., Bovetti, M., Carosso, A. R., Malandrone, F., Carletto, S., \& Benedetto, C. (2020). Psychosocial factors associated with postpartum psychological distress during the Covid-19 pandemic: a cross-sectional study. BMC Pregnancy Childbirth, 20(1), 703. https://doi.org/10.1186/s12884-020-03399-5

Pariente, G., Wissotzky Broder, O., \& Sheiner, E. e. a. (2020). Risk for probable post-partum depression among women during the COVID-19 pandemic. . Arch Womens Ment Health, 23, 767-773. https://doi.org/https://doi.org/10.1007/s00737-020-01075-3

Parker, A. (2021). Reframing the narrative: Black maternal mental health and culturally meaningful support for wellness. Infant Ment Health J. $\underline{\text { https://doi.org/10.1002/imhj.21910 }}$ 
Patrick, S. W., Henkhaus, L. E., Zickafoose, J. S., Lovell, K., Halvorson, A., Loch, S., Letterie, M., \& Davis, M. M. (2020). Well-being of Parents and Children During the COVID-19 Pandemic: A National Survey. Pediatrics, 146(4). https://doi.org/10.1542/peds.2020-016824

Perry, B. L., Aronson, B., \& Pescosolido, B. A. (2021). Pandemic precarity: COVID-19 is exposing and exacerbating inequalities in the American heartland. Proc Natl Acad Sci U S A, 118(8). https://doi.org/10.1073/pnas.2020685118

Pierce, M., Hope, H., Ford, T., Hatch, S., Hotopf, M., John, A., Kontopantelis, E., Webb, R., Wessely, S., McManus, S., \& Abel, K. M. (2020). Mental health before and during the COVID-19 pandemic: a longitudinal probability sample survey of the UK population. The Lancet Psychiatry. https://doi.org/10.1016/S2215-0366(20)30308-4

Pierce, M., McManus, S., Jessop, C., John, A., Hotopf, M., Ford, T., Hatch, S., Wessely, S., \& Abel, K. M. (2020). Says who? The significance of sampling in mental health surveys during COVID-19. Lancet Psychiatry, 7(7), 567-568. https://doi.org/10.1016/S2215-0366(20)30237-6

Prime, H., Wade, M., \& Browne, D. T. (2020). Risk and resilience in family well-being during the COVID-19 pandemic. American Psychologist, 75(5), 631-643. https://doi.org/10.1037/amp0000660

Racine, N., Hetherington, E., McArthur, B. A., McDonald, S., Edwards, S., Tough, S., \& Madigan, S. (2021). Maternal depressive and anxiety symptoms before and during the COVID-19 pandemic in Canada: a longitudinal analysis. Lancet Psychiatry. https://doi.org/10.1016/S2215$\underline{0366(21) 00074-2}$

Racine, N., Plamondon, A., Hentges, R., Tough, S., \& Madigan, S. (2019). Dynamic and bidirectional associations between maternal stress, anxiety, and social support: The critical role of partner and family support. J Affect Disord, 252, 19-24. https://doi.org/10.1016/j.jad.2019.03.083

Razurel, C., \& Kaiser, B. (2015). The role of satisfaction with social support on the psychological health of primiparous mothers in the perinatal period. Women Health, 55(2), 167-186. https://doi.org/10.1080/03630242.2014.979969 
Robinson, E., Sutin, A., Daly, M., \& Jones, A. (2021). A systematic review and meta-analysis of longitudinal cohort studies comparing mental health before versus during the COVID-19 pandemic.

Rogers, A., Obst, S., Teague, S. J., Rossen, L., Spry, E. A., Macdonald, J. A., Sunderland, M., Olsson, C. A., Youssef, G., \& Hutchinson, D. (2020). Association Between Maternal Perinatal Depression and Anxiety and Child and Adolescent Development: A Meta-analysis. JAMA Pediatr. https://doi.org/10.1001/jamapediatrics.2020.2910

Schore, A. (2001). Effects of a secure attachment relationship on right bain development, affect regulation, a nd infant mental health. Infant Mental Health Journal, 22(1-2), 7-66.

Selye, H. (1955). Stress and disease. Science, 122(3171), 625-631.

Sevilla, A., \& Smith, S. (2020). Baby steps: the gender division of childcare during the COVID-19 pandemic. Oxford Review of Economic Policy, 36, S169-S186.

Shafer, K., Scheibling, C., \& Milkie, M. A. (2020). The Division of Domestic Labor before and during the COVID-19 Pandemic in Canada: Stagnation versus Shifts in Fathers' Contributions. Can Rev Sociol, 57(4), 523-549. https://doi.org/10.1111/cars.12315

Shim, R. S. (2020). Mental Health Inequities in the Context of COVID-19. JAMA Netw Open, 3(9), e2020104. https://doi.org/10.1001/jamanetworkopen.2020.20104

Shorey, S., Chee, C. Y. I., Ng, E. D., Chan, Y. H., Tam, W. W. S., \& Chong, Y. S. (2018). Prevalence and incidence of postpartum depression among healthy mothers: A systematic review and metaanalysis. J Psychiatr Res, 104, 235-248. https://doi.org/10.1016/j.jpsychires.2018.08.001

Silverman, M. E., Burgos, L., Rodriguez, Z. I., Afzal, O., Kalishman, A., Callipari, F., Pena, Y., Gabay, R., \& Loudon, H. (2020). Postpartum mood among universally screened high and low socioeconomic status patients during COVID-19 social restrictions in New York City. Sci Rep, 10(1), 22380. https://doi.org/10.1038/s41598-020-79564-9 
Sohr-Preston, S. L., \& Scaramella, L. V. (2006). Implications of Timing of Maternal Depressive Symptoms for Early Cognitive and Language Development. Clinical Child and Family Psychology Review, 9(1), 65-83. https://doi.org/10.1007/s10567-006-0004-2

Spinola, O., Liotti, M., Speranza, A. M., \& Tambelli, R. (2020). Effects of COVID-19 Epidemic Lockdown on Postpartum Depressive Symptoms in a Sample of Italian Mothers. Front Psychiatry, 11, 589916. https://doi.org/10.3389/fpsyt.2020.589916

Staples, L. G., Dear, B. F., Gandy, M., Fogliati, V., Fogliati, R., Karin, E., Nielssen, O., \& Titov, N. (2019). Psychometric properties and clinical utility of brief measures of depression, anxiety, and general distress: The PHQ-2, GAD-2, and K-6. Gen Hosp Psychiatry, 56, 13-18. https://doi.org/10.1016/j.genhosppsych.2018.11.003

Statistics Canada (2021). Household economic well-being during the COVID-19 pandemic, experimental estimates, first quarter to third quarter of 2020. https://www150.statcan.gc.ca/n1/dailyquotidien/210301/cg-b003-eng.htm

Stojanov, J., Stankovic, M., Zikic, O., Stankovic, M., \& Stojanov, A. (2020). The risk for nonpsychotic postpartum mood and anxiety disorders during the COVID-19 pandemic. Int J Psychiatry Med, 91217420981533. https://doi.org/10.1177/0091217420981533

Suhariati, H. I., Yuswatiningsih, E., Hasanuddin, A., Tabara, R., Rahmawati, A., Sayekti, S., Setiarini, D. A. K., Pitayanti, A., Maunaturrohmah, A., \& Achmad, H. (2020). Coping strategy relationship with the answers of moms who had pre-school children during pandemic COVID 19. International Journal of Pharmaceutical Research, 12, 3943-3948.

Sun, G., Wang, Q., Lin, Y., Li, R., Yang, L., Liu, X., Peng, M., Wang, H., Yang, X., Ren, W., Yang, H., \& Cheng, Y. (2020). Perinatal Depression of Exposed Maternal Women in the COVID-19 Pandemic in Wuhan, China. Front Psychiatry, 11, 551812. https://doi.org/10.3389/fpsyt.2020.551812

Suzuki, S. (2020). Psychological status of postpartum women under the COVID-19 pandemic in Japan. $J$ Matern Fetal Neonatal Med, 1-3. https://doi.org/10.1080/14767058.2020.1763949 
Tomfohr-Madsen, L. M., Racine, N., Giesbrecht, G. F., Lebel, C., \& Madigan, S. (2021). Depression and anxiety in pregnancy during COVID-19: A rapid review and meta-analysis. Psychiatry Research, 300, 113912. https://doi.org/https://doi.org/10.1016/j.psychres.2021.113912

Van Lieshout, R. J., Savoy, C. D., Boyle, M. H., Georgiades, K., Jack, S. M., Niccols, A., Whitty, H., \& Lipman, E. L. (2020). The Mental Health of Young Canadian Mothers. J Adolesc Health, 66(4), 464-469. https://doi.org/10.1016/j.jadohealth.2019.10.024

Vesga-Lopez, O., Blanco, C., Keyes, K., Olfson, M., Grant, B. F., \& Hasin, D. S. (2008). Psychiatric disorders in pregnant and postpartum women in the United States. Arch Gen Psychiatry, 65(7), 805-815. https://doi.org/10.1001/archpsyc.65.7.805

Vindegaard, N., \& Benros, M. E. (2020). COVID-19 pandemic and mental health consequences: Systematic review of the current evidence. Brain Behav Immun, 89, 531-542. https://doi.org/10.1016/j.bbi.2020.05.048

WHO. (2021). WHO Coronavirus (COVID-19) Dashboard. https://covid19.who.int

Williford, A. P., Calkins, S. D., \& Keane, S. P. (2007). Predicting Change in Parenting Stress Across Early Childhood: Child and Maternal Factors. J Abnorm Child Psychol, 35, 251-263. https://doi.org/https://doi-org.ezproxy.lib.ucalgary.ca/10.1007/s10802-006-9082-3

Yogman, M., Garfield, C. F., \& American Academy of Pediatrics the COMMITTEE ON PSYCHOSOCIAL ASPECTS OF CHILD, H. (2016). Fathers' Roles in the Care and Development of Their Children: The Role of Pediatricians. . Pediatrics, 1, e20161128.

Zanardo, V., Manghina, V., Giliberti, L., Vettore, M., Severino, L., \& Straface, G. (2020). Psychological impact of COVID-19 quarantine measures in northeastern Italy on mothers in the immediate postpartum period. Int J Gynaecol Obstet, 150(2), 184-188. https://doi.org/10.1002/ijgo.13249

Zanardo, V., Tortora, D., Guerrini, P., Garani, G., Severino, L., Soldera, G., \& Straface, G. (2021). Infant feeding initiation practices in the context of COVID-19 lockdown. Early Hum Dev, 152, 105286. https://doi.org/10.1016/j.earlhumdev.2020.105286 
Zoch, G., Bachmann, A., \& Vicari, B. (2021). Who cares when care closes? Care-arrangements and parerntal working conditions during the COVID-19 pandemic in Gerrmany. European Societies,

23. 
Supplemental Table 1: Search Strategy from Ovid MEDLINE(R) and Epub Ahead of Print, In-Process \& Other Non-Indexed Citations and Daily <1946 to March 03, 2021>

\section{\# Searches}

1 Mental Health/

2 mental disorders/ or exp anxiety disorders/ or exp mood disorders/ or neurotic disorders/ or exp "trauma and stressor related disorders"/

3 depression/ or obsessive behavior/ or stress, psychological/ or burnout, psychological/ or anxiety/ or catastrophization/ or psychological distress/ or exp Self-Injurious Behavior/ or adaptation, psychological/ or emotional adjustment/ or emotionalregulation/ or Resilience, Psychological/

4 ((mental* or psych* or behavior* or behaviour* or mood* or panic* or affective or emotion* or neurotic or adjustment or reactive) adj2 (health* or ill* or well* or disease* or disorder* or syndrome* or hygiene or symptom* or disturbance* or dysfunction* or attack* or trauma* or condition* or state* or status* or adapt* or regulat* or adjust* or control*)).tw,kf.

5 (anxiet* or depress* or stress* or distress* or PTSD or posttraumatic or post traumatic or nervous* or neuroses or neurosis or catastrophi* or psychoneuros?s or psycho-neuros?s or phobi* or cyclothymi* or melanchol* or trauma* or obsess* or OCD or dysthymi* or dysphori* or astheni* or psychastheni* or alexithymi* or hysteri* or psychotrauma or burnout or burnout or cothymi* or self-harm or suicid* or parasuicid* or self-injur* or selfmutilat* or self-destructive behavio?r* or well-being or wellbeing or resilien*).tw,kf.

61 or 2 or 3 or 4 or 5

7 exp Coronaviridae Infections/

8 exp Coronavirus/

9 (2019-ncov* or 2019ncov* or 2019n-cov* or coronaviru* or corona viru* or covid or covid-19 or covid19* or ncov* or novel cov* or ncov* or covid2019 or covid 2019 or SARS-COV-2* or SARS-COV2* or SARSCOV-2* or SARSCOV2* or SARSCOV19 or SARSCOV-19 or SARSCOV-19 or SARSCOV-2019 or SARSCOV2019 or SARSCOV-2019 or Wuhan pneumonia or Wuhan virus or severe acute respiratory syndrome or severe acute respiratory disease).tw, kf.

107 or 8 or 9

11 parents/ or fathers/ or mothers/ or single parent/

12 maternal behavior/ or parenting/ or paternal behavior/ or child rearing/

13 Legal Guardians/ or Child Custody/ or Caregivers/

14 (parent* or father* or mother* or stepparent* or step-parent* or dad or dads or mom or moms or stepdad* or step-dad* or stepmom* or step-mom* or stepfather* or step-father* or stepmother* or step-mother* or single-parent* or guardian* or patern* or matern*).tw,kf.

15 (caregiver* or care-giver*).tw,kf.

1611 or 12 or 13 or 14 or 15 
$17 \quad 6$ and 10 and 16

18 limit 17 to $\mathrm{dt}=20200101-20210331$

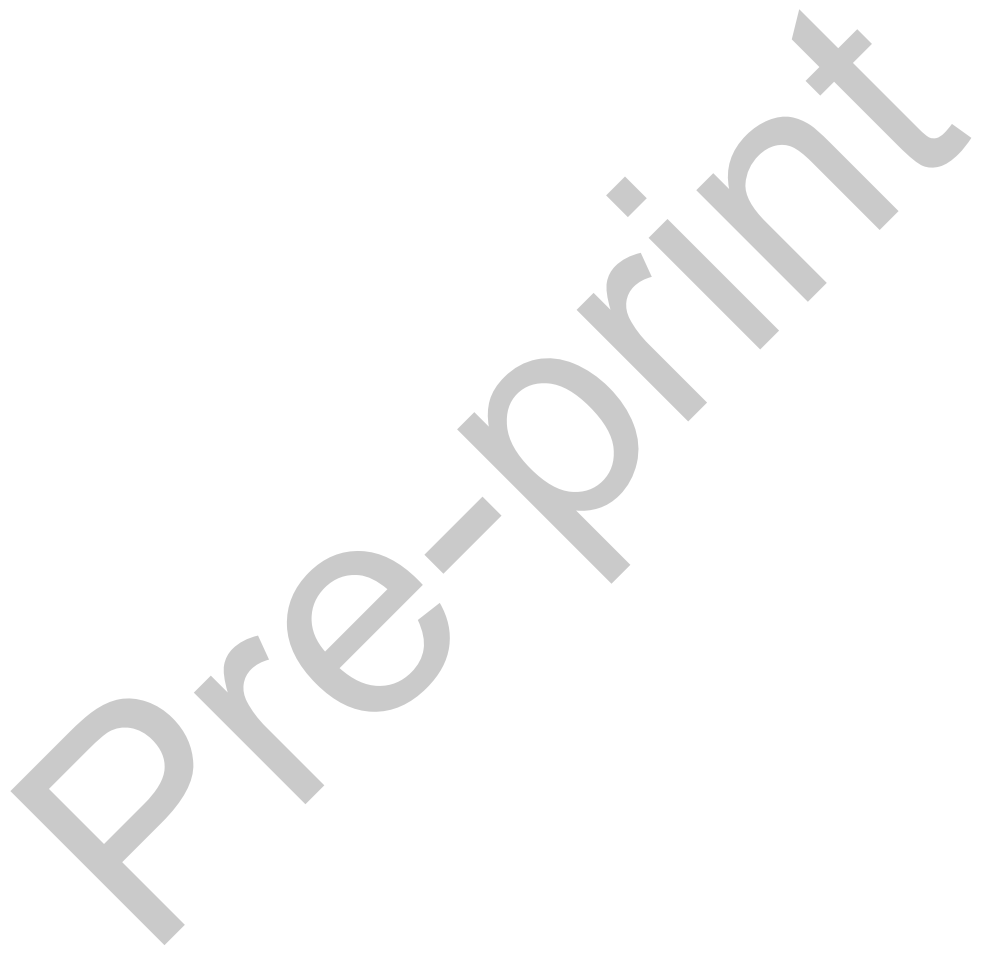


Supplemental Table 2: Study Quality Evaluation Criteria. ${ }^{1}$

\begin{tabular}{|c|c|}
\hline Quality 1:Valid Measure & $\begin{array}{l}\text { Are the depression/anxiety measures } \\
\text { validated questionnaires? } \\
0 \text {-no } \\
1 \text {-yes }\end{array}$ \\
\hline Quality 2:Peer reviewed & $\begin{array}{l}\text { Was the study peer reviewed? } \\
0 \text {-no } \\
1 \text {-yes }\end{array}$ \\
\hline Quality 3:50\% participation & $\begin{array}{l}\text { Did at least } 50 \% \text { of the eligible population } \\
\text { participate? } \\
0 \text {-no } \\
1 \text {-yes }\end{array}$ \\
\hline Quality 4: Objective outcome & $\begin{array}{l}\text { Were the measures of mental health objective } \\
\text { (e.g., a diagnosis) as opposed to self-report? } \\
\text { 0-self-report } \\
\text { 1-objective }\end{array}$ \\
\hline Quality 5: Exposure time & $\begin{array}{l}\text { Did enough time elapse since COVID for } \\
\text { there to be an impact on mental health? } \\
0 \text {-no } \\
1 \text {-yes }\end{array}$ \\
\hline
\end{tabular}

${ }^{1}$ Adapted from the NIH Quality Assessment Tool for Observational Cohort and CrossSectional Studies to evaluate any bias in the study or measurements. This measure is available at https://www.nhlbi.nih.gov/health-topics/study-quality-assessment-tools 
Supplemental Table 3: Quality Assessment of Studies Included.

\begin{tabular}{|c|c|c|c|c|c|c|}
\hline First Author, Year & Valid Measure & Peer Reviewed & $50 \%$ Participation & Objective Outcome & $\begin{array}{l}\text { Exposure } \\
\text { Time }\end{array}$ & $\begin{array}{l}\text { Total } \\
\text { Score } \\
(0-5)\end{array}$ \\
\hline Cameron 2020 & 1 & 1 & 0 & 0 & 1 & 3 \\
\hline Chaves 2021 & 1 & 1 & 0 & 0 & 1 & 3 \\
\hline Fallon 2021 & 1 & 1 & 0 & 0 & 1 & 3 \\
\hline Hamadani 2020 & 1 & 1 & 1 & 0 & 1 & 4 \\
\hline Harrison 2021 & 1 & 1 & 0 & $0>$ & 1 & 3 \\
\hline LoretdeMola 2021 & 1 & 1 & 1 & 0 & 1 & 4 \\
\hline Molgora 2020 & 1 & 1 & 0 & 0 & 1 & 3 \\
\hline Oskovi-Kaplan 2020 & 1 & 1 & 0 & 0 & 1 & 3 \\
\hline Ostacoli 2020 & 1 & 1 & 1 & 0 & 1 & 4 \\
\hline Pariente 2020 & 1 & 1 & 0 & 0 & 1 & 3 \\
\hline Silverman 2020 & 1 & 1 & 1 & 0 & 1 & 4 \\
\hline Spinola 2020 & 1 & 1 & 0 & 0 & 0 & 2 \\
\hline Stojanov 2020 & 1 & 1 & 0 & 0 & 1 & 3 \\
\hline Suhariati 2020 & 1 & 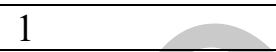 & 0 & 0 & 1 & 3 \\
\hline Sun 2020 & 1 & 1 & 1 & 0 & 1 & 4 \\
\hline Suzuki 2020 & 1 & 1 & 0 & 0 & 1 & 3 \\
\hline Zanardo 2020 & 1 & $1<>$ & 1 & 0 & 1 & 4 \\
\hline Zanardo 2021 & 1 & 1 & 1 & 0 & 1 & 4 \\
\hline
\end{tabular}


Supplemental Figure 1. Funnel plot for studies included in the clinically significant depressive symptoms meta-analysis.

\section{Funnel Plot of Standard Error by Logit event rate}

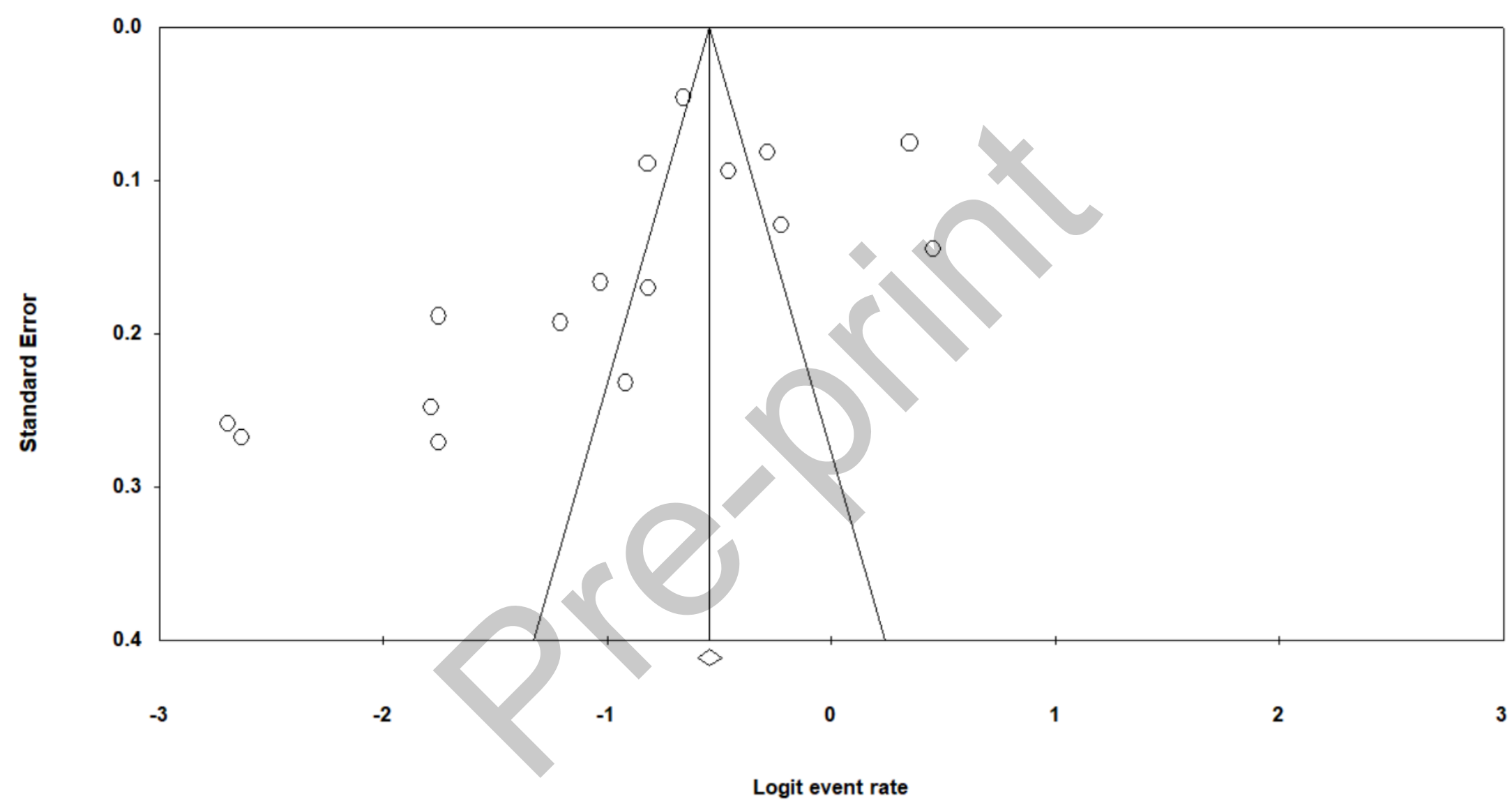

Note. The $\mathrm{x}$-axis represents the effect size (random effects), and the $\mathrm{y}$-axis represents the standard error. The white circles indicate studies included in the meta-analysis. The white diamond represents the observed mean effect size. 
Supplemental Figure 2. Funnel plot for studies included in the clinically significant anxiety symptoms meta-analysis.

\section{Funnel Plot of Standard Error by Logit event rate}

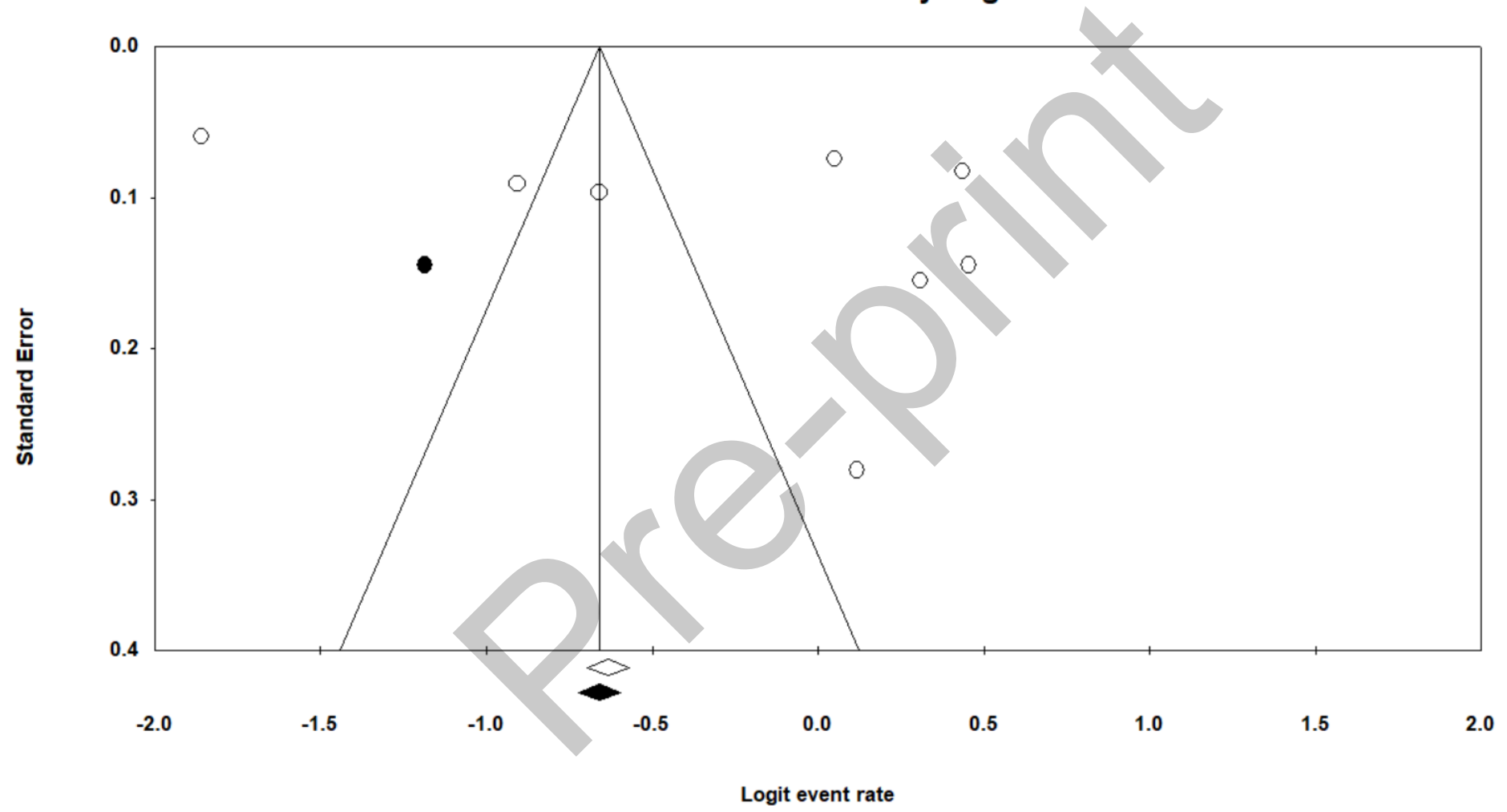

Note. The $\mathrm{x}$-axis represents the effect size (random effects), and the y-axis represents the standard error. The white circles indicate studies included in the meta-analysis. The black circle indicates an imputed study based on publication bias. The white diamond represents the observed mean effect size, and the black diamond represents the adjusted mean effect size when including the imputed study. 